\title{
Mapeamento de Genes de Resistência do Feijoeiro à Ferrugem, Antracnose e Mancha-Angular Usando Marcadores RAPD*
}

\author{
Fábio G. Faleiro ${ }^{1,3 * *}$, Vilmar A. Ragagnin ${ }^{3}$, Ivan Schuster ${ }^{3}$, Ronan X. Corrêa ${ }^{2}$, Pedro I. Good-God ${ }^{3}$, \\ Sérgio H. Brommonshenkel ${ }^{3,4}$, Maurílio A. Moreira ${ }^{3,5}$ \& Everaldo G. Barros ${ }^{3,6}$ \\ 'Embrapa Cerrados, BR 020 Km18, CEP 73301-970, Planaltina, DF, e-mail: ffaleiro@cpac.embrapa.br; \\ ${ }^{2}$ Universidade Estadual de Santa Cruz, Ilhéus, BA; ${ }^{3}$ Instituto de Biotecnologia Aplicada à Agropecuária \\ (BIOAGRO); ${ }^{4}$ Departamento de Fitopatologia; ${ }^{5}$ Departamento de Bioquímica e Biologia Molecular; \\ ${ }^{6}$ Departamento de Biologia Geral, Universidade Federal de Viçosa, CEP 36571-000, Viçosa, MG
}

(Aceito para publicação em 16/08/2002)

Autor para correspondência: Fabio G. Faleiro

FALEIRO, F.G., RAGAGNIN, V.A., SCHUSTER, I., CORRÊA, R.X., GOOD-GOD, P.I., BROMMONSHENKEL, S.H., MOREIRA, M.A. \& BARROS, E.G. Mapeamento de genes de resistência do feijoeiro à ferrugem, antracnose e mancha-angular usando marcadores RAPD. Fitopatologia Brasileira 28:059-066. 2003.

\section{RESUMO}

A organização de diferentes genes de resistência da cultivar Ouro Negro de feijoeiro-comum (Phaseolus vulgaris) à ferrugem, antracnose e mancha-angular foi estudada com o auxílio de marcadores moleculares. Uma população de 154 linhas endogâmicas recombinantes (RIL's) obtidas do cruzamento entre as cultivares Ouro Negro e Rudá foram inoculadas com sete raças fisiológicas de Uromyces appendiculatus, três de Colletotrichum lindemuthianum, e quatro de Phaeoisariopsis griseola. Amostras de DNA de cada uma das RIL's foram amplificadas via PCR utilizando 70 diferentes primers. A análise da segregação da resistência à ferrugem, antracnose e mancha-angular na população de 154 RIL's revelou diferentes modos de herança para a resistência a cada uma das raças fisiológicas. A análise de ligação genética revelou que os diferentes genes de resistência à ferrugem e à antracnose estão no mesmo grupo de ligação. Os genes de resistência à mancha-angular também foram mapeados juntos, porém em outro grupo de ligação. Verificou-se neste trabalho que a utilidade dos marcadores RAPD, previamente identificados como ligados a genes de resistência do feijoeiro a doenças foi restrita. Apenas cinco dos 38 marcadores moleculares testados foram validados na população de RIL's como ligados aos genes de resistência à ferrugem e à antracnose. Três novos marcadores (OBA16 $_{669}$ e OBA16 $6_{583}$ a 10,4 cM em acoplamento e OAD9 ${ }_{3210}$ a 13,9 cM em repulsão) ligados ao bloco gênico de resistência da cultivar Ouro Negro à mancha-angular foram identificados.

Palavras-chave adicionais: Colletotrichum lindemuthianum, Phaeosariopsis griseola, Uromyces appendiculatus, Phaseolus vulgaris.

\section{ABSTRACT}

Mapping rust, anthracnose and angular leaf spot resistance genes in common bean using RAPD markers

Molecular markers were used to study the organization of rust, anthracnose and angular leaf spot resistance genes in common bean (Phaseolus vulgaris) Ouro Negro cultivar. A segregant population of 154 recombinant inbred lines (RIL's) from the crossing between Ouro Negro and Rudá cultivars was inoculated under controlled conditions with seven races of Uromyces appendiculatus, three of Colletotrichum lindemuthianum and four of Phaeoisariopsis griseola. DNA samples of each RIL were amplified by polymerase chain reaction using 70 decamer primers. Segregation analysis of rust, anthracnose and angular leaf spot resistance suggested specific resistance inheritance to each physiologic race. Genetic linkage analysis revealed the grouping of different rust and anthracnose resistance genes in the same linkage group. Angular leaf spot resistance genes also were mapped together, but in another linkage group. The utility of RAPD markers linked to common bean resistance genes, previously identified in the literature, was restricted. Only five out of 38 molecular markers tested were validated on the RIL's population as linked to rust and anthracnose resistance genes. Three new molecular markers (OBA16 ${ }_{669}$ and OAB $16_{583}$ to $10.4 \mathrm{cM}$ in coupling and OAD93210 to $13.9 \mathrm{cM}$ in repulsion) were identified that are linked to to the angular leaf spot resistance gene block in Ouro Negro cultivar.

\section{INTRODUÇÃO}

Os genes que conferem resistência raça-específica (genes R) atuam diferenciadamente com o genótipo do patógeno (raça fisiológica) e de acordo com a teoria gene-a-

\footnotetext{
* Parte da Tese de Doutorado do primeiro autor. Universidade Federal de Viçosa. (2000). Auxílio financeiro PADCT/FINEP e FAPEMIG

**Bolsista da CAPES
}

gene. Segundo Flor (1955), para cada gene que condiciona uma reação de resistência no hospedeiro, existe um gene complementar no patógeno que condiciona a avirulência. A evolução das interações gene-a-gene tem como conseqüência uma diversidade de genes $\mathrm{R}$ em diferentes indivíduos de uma espécie hospedeira e uma correspondente diversidade de genes de avirulência em diferentes raças do patógeno (Staskawicz et al., 1995). 
$\mathrm{O}$ estudo da diversidade de genes $\mathrm{R}$, bem como a organização genômica de tais genes, têm despertado o interesse de diferentes pesquisadores porque tais estudos abrem novas perspectivas para o entendimento da evolução dos genes $\mathrm{R}$ e para o desenvolvimento de estratégias eficientes para o melhoramento visando resistência a doenças. Nestes estudos, verifica-se que as plantas possuem muitos genes raçaespecíficos, os quais são mapeados em poucos locos, e que tais locos podem ser constituídos por genes isolados, por genes ligados e organizados de forma seqüencial e por genes que contêm diferentes alelos (Pryor \& Ellis, 1993).

O número de genes $\mathrm{R}$, bem como o mapeamento de tais genes, têm sido determinados para diferentes patossistemas (Pryor \& Ellis, 1993). No caso do feijoeiro comum (Phaseolus vulgaris L.), com o advento dos marcadores moleculares, os estudos visando o mapeamento de diferentes genes $\mathrm{R}$, aumentaram muito nos últimos anos (Kelly \& Miklas, 1998). Recentemente, Corrêa (1999) iniciou o estudo da organização de diferentes genes de resistência da cultivar Ouro Negro com o auxílio de marcadores moleculares RAPD. Esta cultivar tem apresentado resistência a diferentes raças de Uromyces appendiculatus (Pers.:Pers.) Unger (Faleiro et al., 1996; Faleiro et al., 1999a), Colletotrichum lindemuthianum (Sacc. \& Magnus) Lams.-Scrib. (Lanza et al., 1997) e Phaeoisariopsis griseola (Sacc.) Ferraris (Nietsche, 1997; Faleiro et al., 2001a) em condições de casa de vegetação e campo (Vieira et al., 1992). Corrêa (1999), utilizando a técnica de inoculações múltiplas com diferentes raças fisiológicas de $U$. appendiculatus, $C$. lindemuthianum e $P$. griseola em populações $\mathrm{F}_{2}$ derivadas do cruzamento entre Ouro Negro e US Pinto 111 e as respectivas famílias $F_{2: 3}$, demonstrou que a resistência a diferentes raças de $U$. appendiculatus e $C$. lindemuthianum presente em Ouro Negro é conferida por um bloco de genes e que os genes de resistência às raças 63.39 e 31.23 de $P$. griseola são independentes.

Este trabalho foi desenvolvido com dois objetivos principais: a) complementar os estudos da organização dos diferentes genes de resistência da cultivar Ouro Negro, analisando a segregação da resistência em uma população de 154 linhas endogâmicas recombinantes (RIL's) e b) validar a utilização de diferentes marcadores moleculares, previamente identificados como ligados a genes de resistência do feijoeiro comum à ferrugem, antracnose e mancha-angular.

\section{MATERIAL E MÉTODOS}

\section{Material genético}

A população segregante composta por 154 RIL's de feijoeiro comum foi originada do cruzamento entre a cultivar resistente Ouro Negro e a cultivar Rudá. A cultivar Rudá apresenta grão tipo carioca e ótimas qualidades agronômicas, contudo é suscetível a várias raças fisiológicas dos fungos causadores da ferrugem, antracnose e mancha-angular. A confirmação dos cruzamentos foi feita utilizando a cor de flor como gene marcador. Foram obtidas, aproximadamente 40 sementes $F_{1}$, as quais foram semeadas em casa de vegetação. Uma amostra de 160 sementes $F_{2}$ foi avançada até a geração $\mathrm{F}_{7}$ utilizando o método do descendente de uma única semente ou SSD (Single Seed Descent). Conforme sugerido por Brim (1966), foram semeadas três sementes de cada planta $\mathrm{F}_{2}$ para assegurar a germinação. Após a emergência, uma única planta foi preservada. Tal procedimento foi repetido nas gerações seguintes até a geração $\mathrm{F}_{7}$, quando o nível de homozigose desejado foi obtido. Cada planta $\mathrm{F}_{7}$ obtida a partir de uma planta $F_{2}$ foi considerada uma linhagem endogâmica recombinante (RIL) e suas sementes foram multiplicadas em casa-de-vegetação para avaliar a segregação da resistência às diferentes raças fisiológicas dos fungos causadores da ferrugem, antracnose e mancha-angular.

\section{Avaliação da resistência às doenças}

Para cada raça fisiológica de cada patógeno, uma semente de cada RIL e dos genitores, Rudá e Ouro Negro, foram semeadas em casa-de-vegetação. As sementes foram pré-germinadas em papel germitex a $36{ }^{\circ} \mathrm{C}$ e, após a emissão da radícula, transferidas para bandejas plásticas contendo uma mistura de solo e esterco curtido, na proporção de $4: 1$, adubada

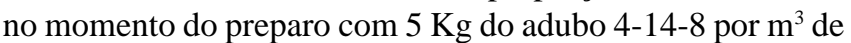
substrato. Em cada bandeja foram plantadas 31 RIL's. As plantas foram mantidas em casa-de-vegetação, antes da inoculação.

Para avaliar a resistência a $U$. appendiculatus foram utilizadas as seguintes raças fisiológicas identificados por Faleiro et al. (1999b) e re-classificadas por Faleiro et al. (1999c): 32 (32132212), 45 (33121211), 46 (33122211), 47 (33131113), 49 (33132212), 52 (33222232) e 56 (33232232). As metodologias de produção de inóculo e inoculação foram as mesmas descritas por Faleiro et al. (1999b). Para avaliação dos sintomas, foi estimado o tamanho médio das pústulas (TMP), quando se completou o período latente. Foram considerados seis graus de reação: 1- ausência de pústulas; 2- manchas necróticas sem esporulação; 3- pústulas esporulando com diâmetro < $300 \mu \mathrm{m}$; 4- pústulas esporulando com diâmetro de $300 \mu \mathrm{m}$ a $499 \mu \mathrm{m}$; 5- pústulas esporulando com diâmetro de $500 \mu \mathrm{m}$ a $800 \mu \mathrm{m}$ e 6- pústulas esporulando com diâmetro $>800 \mu \mathrm{m}$. O tipo de reação foi determinado mediante observação visual, sendo utilizado, como auxílio nas observações, o diagrama de representação gráfica do tipo de reação, idealizado por Castaño (1985). As plantas com predominância de pústulas $>300 \mu \mathrm{m}$ foram consideradas suscetíveis.

Para avaliar a resistência a $C$. lindemuthianum foram utilizadas as raças fisiológicas 73, 81 e 89 , sendo as culturas monospóricas originais cedidas pela Embrapa - Arroz e Feijão. O preparo do inóculo e a inoculação seguiram a metodologia descrita por Pio-Ribeiro \& Chaves (1975). Após a inoculação e rápida secagem ao ar, as plantas foram incubadas por cinco dias na câmara de nevoeiro $\left(20 \pm 1^{\circ} \mathrm{C}\right.$ e $>95 \%$ de umidade relativa), sob fotoperíodo de $12 \mathrm{~h}$. Após esse período, foram novamente transferidas para a casa de vegetação $\left(20 \pm 5^{\circ} \mathrm{C}\right)$, onde permaneceram até serem avaliadas. A avaliação dos sintomas da antracnose foi feita dez dias após a inoculação, com base na escala de 1 a 9 descrita por Pastor-Corrales 
(1992). As plantas que apresentaram graus de reação maiores que 3 foram consideradas suscetíveis.

Para avaliar a resistência a $P$. griseola foram utilizadas as raças fisiológicas 31.23, 31.55, 63.31 e 63.19, identificadas por Nietsche (1997). A metodologia de produção de inóculo e inoculação foram as mesmas descritas por Nietsche (1997). A avaliação dos sintomas da mancha-angular foi feita 15 dias após a inoculação, com base em uma escala de severidade de nove graus (Van Schoonhoven \& Pastor-Corrales, 1987). As plantas que apresentaram graus de reação maiores que 3 foram consideradas suscetíveis.

\section{Análise dos marcadores moleculares}

Amostras de DNA de folhas de cada uma das 154 RIL's, do genitor resistente (Ouro Negro) e do genitor suscetível (Rudá), foram extraídas de acordo com a metodologia de Doyle \& Doyle (1990) e amplificadas com 70 "primers" diferentes, 37 dos quais, de acordo com a literatura, geraram marcadores RAPD e SCAR, previamente identificados, como ligados a genes de resistência do feijoeiro comum à ferrugem, antracnose e mancha-angular (Tabela 1). Os primers que revelaram polimorfismos entre os genitores foram usados para amplificar amostras de DNA das 154 RIL's. Testes de $\chi^{2}$ foram usados para confirmar a herança monogênica dos marcadores moleculares e da resistência a cada uma das raças fisiológicas de $U$. appendiculatus, C. lindemuthianum e P. griseola. $\mathrm{O}$ cálculo da freqüência de recombinação e das distâncias genéticas entre os marcadores moleculares e os genes de resistência, bem como a determinação do posicionamento dos marcadores foram feitas utilizando a função de mapeamento de Kosambi com o auxílio do programa MAPMAKER (Lander et al., 1987; Lincoln et al., 1992).

\section{RESULTADOS E DISCUSSÃO}

A análise da segregação da resistência à ferrugem, antracnose e mancha-angular na população de 154 RIL's está apresentada na Tabela 2.

No caso da ferrugem, verificou-se que a segregação da resistência às raças fisiológicas 32, 47, 49, 52 e 56 é típica de uma característica monogênica, enquanto às raças 45 e 46 de uma característica governada por dois genes principais. Todos os genes de resistência foram herdados a partir da cultivar Ouro Negro. Faleiro et al. (1996, 1999a, 2001a, 2001b) destacaram esta cultivar como importante fonte de genes de resistência à ferrugem. Estudos preliminares de alelismo indicam que o bloco gênico de resistência presente na cultivar Ouro Negro difere dos identificados até o momento, entretanto, sugerem que o mesmo pode ser um alelo do bloco gênico Ur-11, o qual está presente nas PI's 181996 e 190078 (Stavely, J.R., comunicação pessoal). Faleiro et al. (2000) levantaram a hipótese que o bloco gênico presente na cultivar Ouro Negro era semelhante ao bloco gênico $U r$-5, presente na linhagem B-190, baseando-se nas semelhanças fenotípicas entre 'Ouro Negro' e 'B-190' e na presença, em ambos genótipos, de um marcador molecular, identificado por Haley et al. (1993) e gerado pelo primer OPF10, ligado à resistência à ferrugem. Corrêa (1999) verificou que a cultivar México 309 , que possui o bloco gênico $U r-5$, também apresentava o mesmo marcador molecular. A presença de tal marcador molecular não garante que 'Ouro Negro', 'B-190' e 'México 309 ' tenham os mesmos genes no loco marcado, embora possa sugerir, juntamente com os dados fenotípicos, que tais genótipos possuem genes de resistência à ferrugem organizados de forma similar. Recentemente, Alzate-Marin et al. (2002) mostraram que o bloco gênico presente na cultivar Ouro Negro é diferente do $U r-5$ e $U r-11$.

No caso da antracnose, a segregação da resistência das RIL's às raças fisiológicas 73, 81 e 89 evidencia uma herança monogênica da resistência a cada uma das raças. Como ocorreu para a resistência à ferrugem, todos os genes foram herdados a partir da cultivar Ouro Negro. Na tentativa de entender a origem desses genes de resistência, Corrêa (1999) verificou que as cultivares Cornell 49.242, México 222 e AB 136, que possuem os genes de resistência à antracnose $\mathrm{Co}-2, \mathrm{Co}-3$ e $\mathrm{Co}-6$, respectivamente, apresentavam os marcadores SCARF10 e SCARBA8. Esses marcadores moleculares apresentam-se ligados aos genes de resistência à antracnose presentes na cultivar Ouro Negro. Estudos de alelismo envolvendo esses genótipos estão sendo conduzidos para um melhor entendimento da origem dos genes de resistência da cultivar Ouro Negro.

No caso da mancha-angular, a análise de segregação dos genes de resistência às quatro raças fisiológicas testadas mostra diferentes modos de herança. Para as raças fisiológicas 31.55 e 63.31, a herança é tipicamente monogênica, enquanto que para a raça fisiológica 63.19 , a resistência é conferida por dois genes principais. No caso da resistência à raça fisiológica 31.23, a segregação de uma planta resistente para cada três suscetíveis indica o envolvimento de dois genes complementares, ou seja, o fenótipo de resistência somente é manifestado com a presença dos dois genes. Corrêa (1999) analisando a herança da resistência da cultivar Ouro Negro à raça fisiológica 31.23 em uma população $F_{2}$, levantou a hipótese que a resistência era determinada por um gene recessivo. Tal hipótese não foi confirmada na população de RIL's, uma vez que a segregação de uma planta suscetível para cada planta resistente não foi verificada.

De acordo com a análise de ligação genética entre os genes de resistência que segregaram na razão monogênica de 1:1 (Figura 1), verifica-se que os genes de resistência às raças fisiológicas 32, 47, 49, 52 e 56 de $U$. appendiculatus estão proximamente ligados. Tal ligação também é verificada para os genes de resistência às raças fisiológicas 73, 81 e 89 de $C$. lindemuthianum e às raças fisiológicas 31.55 e 63.31 de $P$. griseola. $\mathrm{O}$ agrupamento de genes de resistência já foi relatado em diversas plantas. O exemplo típico é o loco $M$ de resistência à ferrugem do linho (Linum usitatissimum L.) causada pelo fungo Melampsora lini (Ehrenb.) Desmag. Neste loco, arranjos em tandem de genes $\mathrm{R}$ relacionados com diferentes especificidades são encontrados no genoma da planta (Ellis et al., 1988). A ocorrência de um pareamento 
F.G. Faleiro et al.

TABELA 1 - Marcadores moleculares ligados a genes de resistência do feijoeiro-comum (Phaseolus vulgaris) à ferrugem, antracnose e mancha-angular

\begin{tabular}{|c|c|c|c|c|c|}
\hline Marcador & $\begin{array}{l}\text { Distância (cM) } \\
\text { e orientação* }\end{array}$ & $\begin{array}{c}\text { Gene de } \\
\text { resistência }\end{array}$ & Doença ** & $\begin{array}{c}\text { Fonte de } \\
\text { resistência }\end{array}$ & Referência \\
\hline OF10 $0_{530}$ & 1,9 - rep. & Co- 1 & antracnose & Michigan DRK & Young and Kelly (1997) \\
\hline $\mathrm{OQ} 4_{1440}$ & 5,5 - acop. & $\mathrm{Co}-2$ & antracnose & Cornell 49242 & Young and Kelly (1996) \\
\hline $\mathrm{OH} 2 \mathrm{O}_{450}$ & $0,5-$ acop. & Co-2 & antracnose & Cornell 49242 & AdamBlondon et al. (1994) \\
\hline $\mathrm{OY} 20_{830}$ & sem recomb. & Co-4 & antracnose & TO & Alzate-Marin et al. (1999a) \\
\hline $\mathrm{OC} 8_{900}$ & 9,7 - acop. & $\mathrm{Co}-4$ & antracnose & TO & Alzate-Marin et al. (1999a) \\
\hline $\mathrm{OB} 3_{1800}$ & 3,7 - rep. & Co-4 & antracnose & TO & Alzate-Marin et al. (1999a) \\
\hline $\mathrm{OH} 18_{830}$ & 9,2 - acop. & $\mathrm{Co}-4^{2}$ & antracnose & G 2333 & Alzate-Marin et al. (1999b) \\
\hline OAS13950 & sem recomb. & $\mathrm{Co}-4^{2}$ & antracnose & SEL 1308 & Young et al. (1998) \\
\hline OAL9 9740 & 4,5 - acop. & $\mathrm{Co}-4^{2}$ & antracnose & G 2333 & Young et al. (1998) \\
\hline $\mathrm{OAB}_{450}$ & $5,9-$ acop. & Co-5 & antracnose & TU, G 2333, SEL 1360 & Young and Kelly (1997) \\
\hline $\mathrm{OAH} 1_{780}$ & 12,3 - acop. & Co- 6 & antracnose & $\mathrm{AB} 136$ & Young and Kelly (1997) \\
\hline OAK $20_{890}$ & 7,3 - rep. & Co-6 & antracnose & Catrachita & Young and Kelly (1997) \\
\hline OAZ20 940 & $7,1-$ acop. & Co-6 & antracnose & AB 136 & Alzate-Marin et al. (1999a) \\
\hline $\mathrm{OAZ}_{560}$ & $8,5-$ acop. & Co-6 & antracnose & AB 136 & Alzate-Marin et al. (1999c) \\
\hline OAZ9950 & 20,4 - rep. & Co-6 & antracnose & AB 136 & Alzate-Marin et al. (1999c) \\
\hline $\mathrm{OK} 14_{620}$ & $2,2-$ acop. & $U r-3$ & ferrugem & NEP-II & Haley et al. (1994) \\
\hline $\mathrm{OAC} 2 \mathrm{O}_{490}$ & sem recomb. & $U r-3^{2}$ & ferrugem & PI 181996 & Johnson et al. (1995) \\
\hline OAE 19890 & 6,2 - rep. & $U r-3^{2}$ & ferrugem & PI 181996 & Johnson et al. (1995) \\
\hline $\mathrm{OA} 14_{1100}$ & sem recomb. & $U r-4$ & ferrugem & Early Gallatin & Miklas et al. (1993) \\
\hline OF $10_{970}$ & $2,1-$ acop. & $U r-5$ & ferrugem & México 309 & Haley et al. (1993) \\
\hline $\mathrm{OI} 19_{460}$ & sem recomb. & $U r-5$ & ferrugem & México 309 & Haley et al. (1993) \\
\hline OAA $11_{500}$ & sem recomb. & $U r-7$ & ferrugem & Jules (Tara) & Park et al. (1999) \\
\hline $\mathrm{OAD} 12_{550}$ & sem recomb. & $U r-7$ & ferrugem & Jules (Tara) & Park et al. (1999) \\
\hline OAF $17_{900}$ & sem recomb. & $U r-7$ & ferrugem & Jules (Tara) & Park et al. (1999) \\
\hline $\mathrm{OAB} 16_{850}$ & 2,2 - acop. & $U r-7$ & ferrugem & Jules (Tara) & Park et al. (1999) \\
\hline $\mathrm{OAD}_{550}$ & $2,2-$ acop. & $U r-7$ & ferrugem & Jules (Tara) & Park et al. (1999) \\
\hline OJ13 1800 & $5,0-$ acop. & $U r-9$ & ferrugem & Pompadour Checa & Jung et al. (1996) \\
\hline $\mathrm{SCAR}_{\mathrm{F}} \mathrm{F} 10_{1050}$ & $6,9-$ acop. & $(?)$ & ferrugem & Ouro Negro & Corrêa et al. (2000) \\
\hline${ }_{\mathrm{SCAR}} \mathrm{BA} 8_{560}$ & 6,0 - acop. & (?) & ferrugem & Ouro Negro & Corrêa (1999) \\
\hline OAJ $18_{560}$ & 11,1 - acop. & $(?)$ & ferrugem & Ouro Negro & Corrêa (1999) \\
\hline $\mathrm{OX}-11_{550}$ & 5,8- acop. & $(?)$ & ferrugem & Ouro Negro & Faleiro et al. (2000) \\
\hline $\mathrm{OE} 4_{500}$ & 5,8 - acop. & $\begin{array}{c}\text { Resistência à raça } \\
63.39\end{array}$ & man. ang. & MAR-2 & Ferreira et al. (1999) \\
\hline $\mathrm{OH} 13_{490}$ & 5,5 - acop. & Phg-1 & man. ang. & AND277 & Carvalho et al. (1998) \\
\hline $\mathrm{ON} 2_{890}$ & $5,9-$ acop. & Phg-2 & man. ang. & Mexico 54 & Sartorato et al. (1999a) \\
\hline $\mathrm{OAC} 14_{2400}$ & $6,6-$ acop. & Phg-2 & man. ang. & Mexico 54 & Sartorato et al. (1999a) \\
\hline $\operatorname{SCAR} \mathrm{N} 2890$ & 5,9- acop. & Phg-2 & man. ang. & Mexico 54 & Sartorato et al. (1999b) \\
\hline OAA $19_{400}$ & $10,0-$ acop. & $\begin{array}{c}\text { Resistência à raça } \\
63.39\end{array}$ & man. ang. & Ouro Negro & Corrêa (1999) \\
\hline $\mathrm{OM} 2_{425}$ & $5,6-$ acop. & $\begin{array}{c}\text { Resistência à raça } \\
63.23\end{array}$ & man. ang. & Ouro Negro & Corrêa (1999) \\
\hline
\end{tabular}

* acop. = ocoplamento; rep. = repulsão; recomb. = recombinantes

** man. ang. = mancha-angular

desigual de cromossomos homólogos na meiose leva à evolução de famílias multigênicas por duplicação do segmento contendo o gene ancestral. Análises moleculares do loco $\mathrm{N}$ de resistência ao vírus do mosaico do fumo (Tobacco mosaic virus, TMV) em fumo (Nicotiana tabacum L.) e o loco Cf-9 em tomate (Lycopersicon esculentum Mill.) também têm revelado uma família de genes agrupados (Jones et al., 1994; Whitham et al., 1994).

A análise de ligação genética também mostra que os genes de resistência à ferrugem encontram-se no mesmo grupo de ligação que contém os genes de resistência à antracnose. Como todos os genes de resistência à ferrugem e antracnose são herdados a partir de 'Ouro Negro', a piramidação desses genes em cultivares com grão tipo carioca tem sido facilitada no Programa de Melhoramento do Feijoeiro do BIOAGRO/ UFV (Faleiro et al., 2001c).

A amplificação das 154 RIL's com os 70 diferentes "primers" geraram 50 bandas polimórficas, 26 das quais foram geradas pelos "primers" que originaram os marcadores correspondentes (Tabela 1). Das 50 bandas, 43 apresentaram segregação monogênica (1:1) e foram utilizadas na análise de ligação genética com os genes de resistência. Das 43 bandas polimórficas, nove foram mapeadas nos grupos de ligação que contém os genes de resistência (Figura 1).

Neste trabalho, verificou-se que a utilidade dos marcadores RAPD, previamente identificados como ligados a genes 
Mapeamento de genes de resistência do feijoeiro à ferrugem, antracnose...

TABELA 2 - Caracterização fenotípica das 154 RIL's e dos progenitores do feijoeiro comum (Phaseolus vulgaris) 'Ouro Negro' (ON) e 'Rudá' quanto à resistência à ferrugem, antracnose e mancha angular

\begin{tabular}{|c|c|c|c|c|c|c|}
\hline \multirow{2}{*}{ Raça fisiológica } & \multicolumn{2}{|c|}{ Nota } & \multirow{2}{*}{$\begin{array}{c}\text { Razão teórica nas } \\
\text { RIL's* }\end{array}$} & \multirow{2}{*}{$\begin{array}{c}\text { Freqüência } \\
\text { observada }\end{array}$} & \multirow{2}{*}{$\chi^{2}$} & \multirow{2}{*}{ Prob. } \\
\hline & ON & Rudá & & & & \\
\hline $32(32132212)^{U a}$ & 3 & 5 & $1: 1$ & $85: 69$ & 1,662 & 19,73 \\
\hline $45(33121211)^{U a}$ & 3 & $4 ; 3$ & $3: 1$ & 111:42 & 0,49 & 48,38 \\
\hline $46(33122211)^{U a}$ & 3 & $\begin{array}{c}4,3 \\
4\end{array}$ & $\begin{array}{l}5.1 \\
3: 1\end{array}$ & $114: 39$ & $\begin{array}{l}0,49 \\
0,02\end{array}$ & $\begin{array}{l}40,00 \\
88,86\end{array}$ \\
\hline $47(33131113)^{U a}$ & 3 & $\begin{array}{l}4 \\
5\end{array}$ & $\begin{array}{l}5.1 \\
1: 1\end{array}$ & $\begin{array}{l}114.59 \\
80: 74\end{array}$ & 0,234 & $\begin{array}{l}00,00 \\
62,87\end{array}$ \\
\hline $49(33132212)^{U a}$ & 3 & 5 & $\begin{array}{l}1.1 \\
1: 1\end{array}$ & $82: 72$ & 0,649 & 42,03 \\
\hline $52(33222232)^{U a}$ & 3 & 4 & $1: 1$ & $79: 75$ & 0,104 & 74,72 \\
\hline $56(33232232)^{U a}$ & 3 & 6 & $1: 1$ & $80: 72$ & 0,421 & 51.64 \\
\hline $73^{C l}$ & 1 & 7 & $1: 1$ & $87: 67$ & $\begin{array}{l}0,421 \\
2,597\end{array}$ & $\begin{array}{l}J 1,04 \\
10.70\end{array}$ \\
\hline $81^{C l}$ & 1 & 9 & $1: 1$ & $81: 73$ & 0,416 & 51.91 \\
\hline $89^{C l}$ & 1 & 9 & $\begin{array}{l}1.1 \\
1: 1\end{array}$ & $89: 65$ & 3,74 & 5,31 \\
\hline $31.23^{P g}$ & 8 & 2 & $1: 3$ & $45: 101$ & 2,639 & 10,42 \\
\hline $31.55^{P g}$ & 2 & 7 & $1: 1$ & $84: 63$ & 3,00 & 8,33 \\
\hline $63.31^{P g}$ & 1 & 5 & $1: 1$ & $85: 62$ & 3,599 & 5,78 \\
\hline $63.19^{P g}$ & 4 & 2 & $3: 1$ & $98: 46$ & 3,704 & 5,43 \\
\hline
\end{tabular}

Ua Raças fisiológicas de $U$. appendiculatus

${ }^{C l}$ Raças fisiológicas de $C$. lindemuthianum

${ }^{P g}$ Raças fisiológicas de P. griseola

* Razão teórica esperada 1:1 (hipótese da resistência monogênica); 3:1 (hipótese da resistência determinada por dois genes) e 1:3 (hipótese da resistência determinada por dois genes complementares)

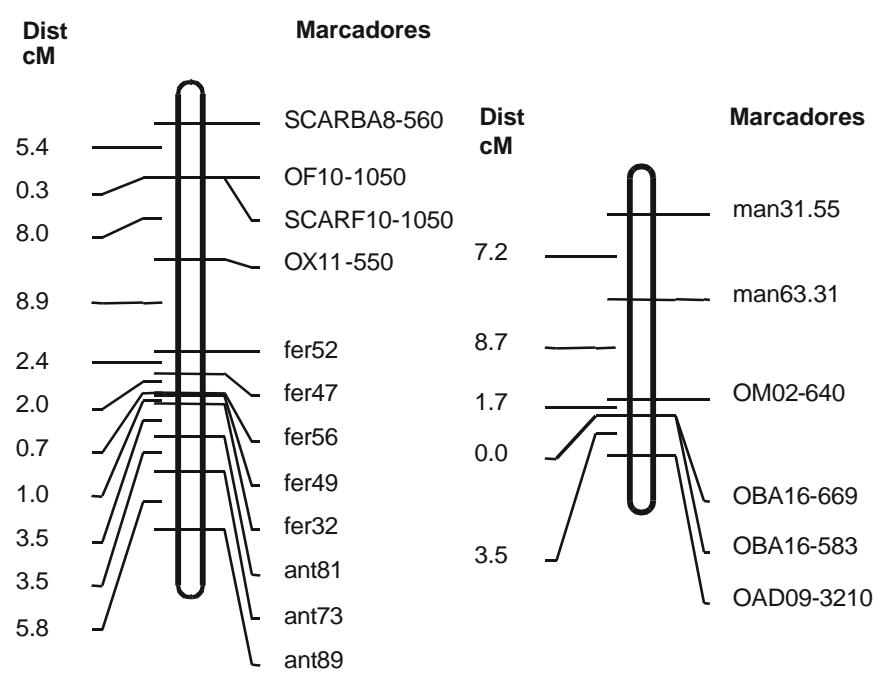

FIG. 1 - Distâncias genéticas e ordem dos locos nos grupos de ligação contendo os genes de resistência à ferrugem (fer52, fer47, fer56, fer49 e fer32), antracnose (ant81, ant73 e ant89) e manchaangular (man31.55 e man63.31) e os marcadores RAPD e SCAR em feijoeiro comum (Phaseolus vulgaris).

de resistência do feijoeiro a doenças, foi restrita. Apenas foram validados nas RIL's, os marcadores identificados em populações segregantes obtidas a partir de cruzamento inicial envolvendo o progenitor resistente 'Ouro Negro': ${ }_{\mathrm{SCAR}} \mathrm{F} 10_{1050}$, ${ }_{\mathrm{SCAR}} \mathrm{BA} 8_{560}, \mathrm{OF} 10_{1050}, \mathrm{OX} 11_{550}$ e OM2 ${ }_{425}$.

Os marcadores OAJ18 ${ }_{560}$ e OAA $19_{400}$, embora tenham sido identificados em populações advindas do progenitor 'Ouro Negro', não foram validados na população de RIL's.
Este fato indica que, para alguns marcadores, a mudança do progenitor suscetível pode comprometer a sua utilidade. Os dois marcadores citados acima foram identificados em populações segregantes obtidas do cruzamento entre 'Ouro Negro' e 'US Pinto 111'. Estudos de diversidade, utilizando marcadores moleculares RAPD, mostraram que a variedade US Pinto 111 é mais distante do 'Ouro Negro' do que a cultivar Rudá (Vasconcelos et al., 1996). Esta maior distância genética permitiu a identificação de maior número de marcadores nas populações 'Ouro Negro' x 'US Pinto 111' do que nas populações 'Ouro Negro' x 'Rudá'.

A comparação dos resultados desse trabalho com os obtidos por Corrêa (1999) mostra que os marcadores ${ }_{\mathrm{SCAR}} \mathrm{F} 10_{1050}$, $_{\mathrm{SCAR}} \mathrm{BA} 8_{560}, \mathrm{OF} 10_{1050}, \mathrm{OX} 11_{550}$ e OM2 ${ }_{425}$ ficaram mais distantes dos genes de resistência na população Ouro Negro x Rudá do que na população Ouro Negro x US Pinto 111, além da mudança de posição de alguns dos marcadores. Como a distância genética é calculada com base na freqüência de recombinação, a maior similaridade entre Ouro Negro e Rudá pode ter favorecido um maior número de recombinações, aumentando assim, as distâncias genéticas. A mudança de posição pode ser explicada com base na ação de diferentes genes "menores" de resistência presentes nas cultivares Rudá e US Pinto 111, os quais levaram a diferentes avaliações fenotípicas da resistência nas diferentes populações.

A utilidade de marcadores moleculares RAPD em populações diferentes daquela onde foram identificados vai depender entre outros fatores do grau de ligação entre o marcador e o gene de interesse e da similaridade genética entre os genitores utilizados nas diferentes populações. Normalmente, a identificação de marcadores e o desenvolvimento de variedades melhoradas têm envolvido diferentes populações e diferentes genitores, o que tem limitado muito o impacto esperado do melhoramento assistido por marcadores (Tanksley 
\& Nelson, 1996).

Três novos marcadores moleculares ligados à resistência do feijoeiro-comum às raças fisiológicas 31.55 e 63.31 de $P$. griseola foram identificados neste trabalho (Figura 2). As amplificações desses fragmentos foram repetitivas e permitiram uma visualização clara em géis de agarose (Figura 2). Os marcadores OBA16 ${ }_{669}$ e OBA16 ${ }_{583}$ estão ligados a 10,4 cM em acoplamento e o OAD9 ${ }_{3210}$ a 13,9 cM em repulsão ao bloco gênico de resistência da cultivar Ouro Negro à manchaangular.

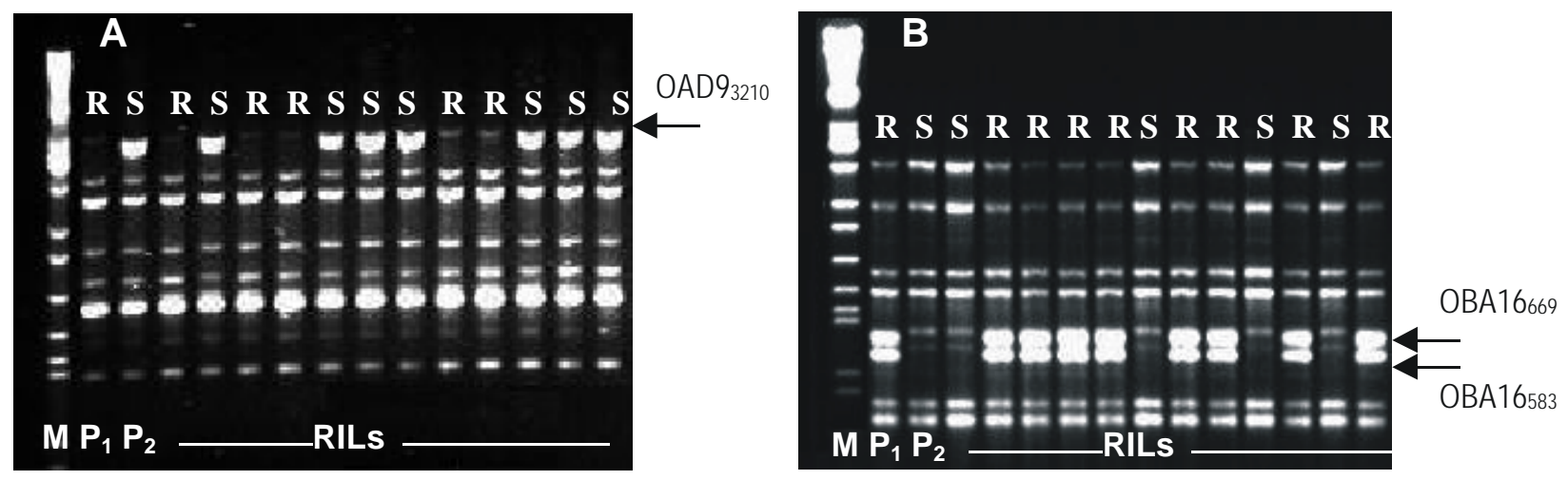

FIG. 2 - Análise eletroforética dos produtos de amplificação do DNA produzidos com os primers OAD9 (A) e OBA16 $(B)$. Em ambos géis, $P_{1}$ corresponde à cultivar Ouro Negro (resistente), $P_{2}$ à cultivar Rudá (suscetível) e RIL's às 12 linhagens resistentes $(R)$ ou suscetíveis $(S)$ da população. Linha $M$ contém DNA de fago-lambda digerido com EcoRI, BamHI e HindIII (marcador de peso molecular). As setas indicam os marcadores OAD9 ${ }_{3210}(\mathrm{~A})$, OBA16 $_{669}$ e BA16 $_{583}($ B).

\section{REFERÊNCIAS BIBLIOGRÁFICAS}

ADAM-BLONDON, A.F., SÉVIGNAE, M., BANNEROT, H. \& DRON, M. SCAR, RAPD and RFLP markers linked to a dominant gene (Are) conferring resistance to anthracnose in common bean. Theoretical and Applied Genetics 88:865-870. 1994.

ALZATE-MARIN, A.L., ARRUDA, M.C.C., MENARIM, H., CHAGAS, J.M., BARROS, E.G. \& MOREIRA, M.A. Identification of RAPD markers linked to resistance genes to anthracnose in common bean cultivars AB136, TO and G2333. Annual Report of the Bean Improvement Cooperative 42:13-14. 1999a.

ALZATE-MARIN, A.L., MENARIM, H., CARVALHO, G.A., PAULA JÚNIOR, T.J., BARROS, E.G. \& MOREIRA, M.A. Improved selection with newly identified RAPD markers linked to resistance gene to four pathotypes of Colletotrichum lindemuthianum in common bean. Phytopathology 89:281-285. 1999b.

ALZATE-MARIN, A.L., MENARIM, H., SOUZA, K.A., CHAGAS, J.M., BARROS, E.G. \& MOREIRA, M.A. Estratégias de separação e identificação dos genes $\mathrm{Co}-4^{2}$ e $\mathrm{Co}-5$ envolvidos na resistência às raças 73 e 89 de Colletotrichum lindemuthianum no cultivar G2333. Resumos, VI Reunião Nacional de Pesquisa de Feijão, Salvador, BA. 1999c. pp. 48-50.

ALZATE-MARIN, A.L., SOUZA, T.L.P.O., FALEIRO, F.G., MOREIRA, M.A. \& BARROS, E.G. Rust resistance gene block in common bean cv. Ouro Negro is not $U r-5$ or $U r-11$. Annual Report of the Bean Improvement Cooperative 45:130-131. 2002.

BRIM, C.A. A modified pedigree method of selection in soybeans. Crop Science 6:220. 1966.

CARVALHO, G.A., PAULA JÚNIOR, T.J., ALZATE-MARIN, A.L., NIETSCHE, S., BARROS, E.G. \& MOREIRA, M.A. Herança da resistência da linhagem AND 277 de feijoeiro-comum à raça 63.23 de Phaeoisariopsis griseola e identificação de marcador RAPD ligado ao gene de resistência. Fitopatologia Brasileira 23:482-485. 1998.

CASTAÑO, J. Manual Standas para cuantificación de daños causados por hongos, bacterias y nematodos en frijol. (Mimeografado). Cali, Colômbia. CIAT. 1985.

CORRÊA, R.X. Genes de resistência a doenças do feijoeirocomum: Identificação de marcadores moleculares, organização e identificação de análogos. (Tese de Doutorado). Viçosa. Universidade Federal de Viçosa. 1999.

CORRÊA, R.X., COSTA, M.R., GOOD-GOD, P.I., RAGAGNIN, V.A., FALEIRO, F.G., VINHADELLI, W.S., MOREIRA, M.A. \& BARROS, E.G. Sequence characterized amplified regions linked to rust resistance genes in the common bean. Crop Science 40:804807. 2000.

DOYLE, J.J. \& DOYLE, J.L. Isolation of plant DNA from fresh tissue. Focus 12:13-15. 1990.

ELLIS, J.C., LAWRENCE, G.J., PEACOCK, W.J. \& PRYOR, A.J. Approaches to cloning plant genes conferring resistance to fungal pathogens. Annual Review of Phytopathology 26:245-263. 1988.

FALEIRO, F.G., PAULA JR., T.J., BARROS, E.G., FREITAS, M.A. \& MOREIRA, M.A. Resistência de cultivares de feijoeiro comum a Uromyces appendiculatus da Zona da Mata de Minas Gerais. Fitopatologia Brasileira 21:123-125. 1996.

FALEIRO, F.G., VINHADELLI, W.S., RAGAGNIN, V.A., PAULA JR., T.J., MOREIRA, E.G. \& BARROS, E.G. Resistência de variedades de feijoeiro-comum a quatro raças de Uromyces appendiculatus. Revista Ceres 46:19-27. 1999a.

FALEIRO, F.G., VINHADELLI, W.S., RAGAGNIN, V.A., ZAMBOLIM, L., PAULA JÚNIOR, T.J., MOREIRA, M.A. \& BARROS, E.G. Identificação de raças fisiológicas de Uromyces 
Mapeamento de genes de resistência do feijoeiro à ferrugem, antracnose...

appendiculatus no estado de Minas Gerais, Brasil. Fitopatologia Brasileira 24:166-169. 1999b.

FALEIRO, F.G., ZAMBOLIM, L., VINHADELLI, W.S., RAGAGNIN, V.A., PAULA JR., T.J., MOREIRA, M.A. \& BARROS, E.G. Sistema simplificado para nomenclatura e classificação de raças fisiológicas de Uromyces appendiculatus. Fitopatologia Brasileira 24:540-545. 1999c.

FALEIRO, F.G., VINHADELLI, W.S., RAGAGNIN, V.A., CORREAA, R.X., MOREIRA, M.A. \& BARROS, E.G. RAPD markers linked to a block of genes conferring rust resistance to the common bean. Genetics and Molecular Biology 23:399-402. 2000.

FALEIRO, F.G., NIETSCHE, S., RAGAGNIN, V.A., BORÉM, A., MOREIRA, M.A. \& BARROS, E.G. Resistência de cultivares de feijoeiro-comum à ferrugem e à mancha-angular em condições de casa-de-vegetação. Fitopatologia Brasileira 26:86-89. 2001 a.

FALEIRO, F.G., RAGAGNIN, V.A., VINHADELLI, W.S., MOREIRA, M.A., STAVELY, J.R. \& BARROS, E.G. Resistência de linhagens de feijoeiro-comum a quatro raças de Uromyces appendiculatus isoladas em Minas Gerais, Brasil. Fitopatologia Brasileira 26:77-80. 2001b.

FALEIRO, F.G., RAGAGNIN, V.A., CARVALHO, G.A., PAULA Jr., T.J., MOREIRA, M.A. \& BARROS, E.G. Development of common bean lines resistant to rust and anthracnose by molecular markers-assisted backcrossing. Annual Report of the Bean Improvement Cooperative 44:109-110. 2001c.

FERREIRA, C.F., BORÉM, A., NIETSCHE, S., BARROS, E.G. \& MOREIRA, M.A. Marcador RAPD associado ao gene de resistência à mancha-angular do feijoeiro. Resumos, VI Reunião Nacional de Pesquisa de Feijão, Salvador, BA. 1999. pp. 60-61.

FLOR, H.H. Host-parasite interactions in flax rust-its genetics and other implications. Phytopathology 45:680-685. 1955.

HALEY, S.D., MIKLAS, P.N., STAVELY, J.R., BYRUM, J. \& KELLY, J.D. Identification of RAPD markers linked to a major rust resistance gene block in common bean. Theoretical and Applied Genetics 86:505-512. 1993.

HALEY, S.D., AFANDOR, L.K., MIKLAS, P.N., STAVELY, J.R. \& KELLY, J.D. Heterogeneous inbred populations are useful as sources of near-isogenic lines from RAPD marker localization.. Theoretical and Applied Genetics 88:337-342. 1994.

JOHNSON, E., MIKLAS, P.N., STAVELY, J.R. \& MARTINEZCRUZADO, J.C. Coupling and repulsion phase RAPDs for markerassisted selection of the PI 181996 rust resistance in common bean. Theoretical and Applied Genetics 90:659-664. 1995.

JONES, D.A., THOMAS, C.M., HAMMOND-KOSACK, K.E., BALINT-KURTI, P.J. \& JONES, J.D.G. Isolation of the tomato Cf-9 gene for resistance to Cladosporium fulvum by transposon tagging. Science 266:789-792. 1994.

JUNG, G., COYNE, D.P., SKROCH, P.W., NIENHUIS, J., ARNAUD-SANTANA, E., BOKOSI, J., ARIYARATHNE, H., STEADMAN, J.R., BEAVER, J. \& KAEPPLER, S. Molecular markers associated with plant architecture and resistance to common blight, web blitht, and rust in common bean. Journal of Amererican Society of Horticultural Science 121:794-803. 1996.

KELLY, J.D. \& MIKLAS, P.N. The role of RAPD markers in breeding for disease resistance in common bean. Molecular Breeding 4:1-11. 1998.

LANDER, E., GREEN, P., ABRAHAMSON, J., BARLON, A.,
DALEY, M., LINCOLN, S. \& NEWBURG, L. MAPMAKER: an interactive computer package for constructing primary genetic linkages maps of experimental and natural populations. Genomics 1:174-181. 1987.

LANZA, M.A., PAULA JR., T.J., VINHADELLI, W.S., MORANDI, M.A.B., BARROS, E.G. \& MOREIRA, M.A. Resistência à antracnose em cultivares de feijoeiro-comum recomendadas para Minas Gerais. Fitopatologia Brasileira 22:560562. 1997.

LINCOLN, S., DALY, M. \& LANDER, E. Constructing genetic maps with MAPMAKER/EXP 3.0. 3rd ed., Whitehead Institute, Cambridge. Technical Report. 1992.

MIKLAS, P.N., STAVELY, J.R. \& KELLY, J.D. Identification and potential use of a molecular marker for rust resistance in common bean. Theoretical and Applied Genetics 85:745-749. 1993.

NIETSCHE, S. Identificação de raças fisiológicas de Phaeoisariopsis griseola e determinação de fontes de resistência em Phaseolus vulgaris. (Tese de Mestrado). Viçosa. Universidade Federal de Viçosa. 1997.

PARK, S.O., COYNE, D.P. \& STEADMAN, J.R. Molecular markers to the $U r-7$ gene conferring specific resistance to rust in common bean. Annual Report of the Bean Improvement Cooperative 42:31-32. 1999.

PASTOR-CORRALES, M.A. Recomendaciones y acuerdos del primer taller de antracnosis en América Latina. In: Pastor-Corrales, M.A. (Ed.) La Antracnosis del Frijol Común, Phaseolus vulgaris, en América Latina. Cali, Colômbia. CIAT. 1992. pp. 240-250.

PIO-RIBEIRO, G. \& CHAVES, G.M. Raças fisiológicas de Colletotrichum lindemuthianum (Sacc. et Magn.) Scrib. que ocorrem em alguns municípios de Minas Gerais, Espírito Santo e Rio de Janeiro. Experientiae 19:59-71. 1975.

PRYOR, T. \& ELLIS, J. The genetic complexity of fungal resistance genes in plants. Advances in Plant Pathology 10:281-305. 1993.

SARTORATO, A., NIETSCHE, S., BARROS, E.G. \& MOREIRA, M.A. Inheritance of angular leaf spot resistance and RAPD markers linked to disease resistance gene in common beans. Annual Report of the Bean Improvement Cooperative 42:21-22. 1999a.

SARTORATO, A., NIETSCHE, S., BARROS, E.G. \& MOREIRA, M.A. SCAR marker linked to angular leaf spot resistance gene in common bean Annual Report of the Bean Improvement Cooperative 42:23-24. 1999b.

STASKAWICZ, B.J., AUSUBEL, F.M., BAKER, B.J., ELLIS, J.G. \& JONES, J.D. Molecular genetics of plant disease resistance. Science 268:661-667. 1995.

TANKSLEY, S.D. \& NELSON, J.C. Advanced backcross QTL analysis: a method for the simultaneous discovery and transfer of valuable QTL's from unadapted germplasm into elite breeding lines. . Theoretical and Applied Genetics 92:191-203. 1996.

VAN SCHOONHOVEN, A. \& PASTOR-CORRALES, M.A. Standard system for evaluation of bean germplasm. Cali, Colombia. CIAT. 1987.

VASCONCELOS, M.J.V., BARROS, E.G., MOREIRA, M.A. \& VIEIRA, C. Genetic diversity of Phaseolus vulgaris L. as determined by DNA-based molecular markers. Brazilian Journal of Genetics 19:447-451. 1996.

VIEIRA, C., ARAÚJO, G.A.A. \& CRUZ, C.D. Comportamento de cultivares de fejão no plantio de outono/inverno. In: Vieira, R.F. 
(Ed.) Projeto Feijão - Relatório 88/92. Viçosa. EPAMIG. 1992. pp. 71-76

WHITHAM, S., DINESH-KUMAR, S.P., CHOI, D., HEHL, R., CORR, C. \& BAKER, B. The product of the tabbaco mosaic virus resistance gene $N$ : similarity to Toll and the interleukin-1 receptor. Cell 78:1101-1115. 1994.

YOUNG, R.A. \& KELLY, J.D. RAPD markers flanking the Are gene for anthracnose resistance in common bean. Journal of
Amererican Society of Horticultural Science 121:37-41. 1996.

YOUNG, R.A. \& KELLY, J.D. RAPD markers linked to three major anthracnose resistance genes in common bean. Crop Science 37:940-946. 1997.

YOUNG, R.A., MELOTTO, M., NODARI, R.O. \& KELLY, J.D. Marker assisted dissection of the oligogenic anthracnose resistance in common bean cultivar, G2333. Theoretical and Applied Genetics 96:87-94. 1998. 